\title{
Pulsate Perfusion of Allografts
}

\author{
Matteo Tozzi, Gabriele Piffaretti, Marco Franchin, \\ and Patrizio Castelli
}

'If one could substitute for the heart a kind of injection of arterial blood, either natural or artificial made, one would succeed easily in maintaining alive indefinitely any part of the body'

Julien Jean Cesar Le Gallois, French physiologist (1770-1814)

\subsection{Introduction}

Since the introduction of organ transplantation surgery more than 50 years ago, static cold storage (SCS) has been considered as the gold standard of organ preservation. However, the discussion on optimal composition of preservation solution and duration and methods of preservation (normothermic vs hypothermic, static vs pulsate) is still open.

Studies on continuous organ perfusion appeared in the late nineteenth century. In the 1930s, Carrel et al. refined those studies with the idea that continuous flow could help in eliminating toxic metabolic products providing nutrients [1]. Thirty years later, Starzl's group employed extracorporeal femoro-femoral canine perfusion for sub-normothermic preservation with satisfactory results. Belzer et al. combined the principle of continuous flow with hypothermia, with the

M. Tozzi · G. Piffaretti · M. Franchin $(\bowtie) \cdot$ P. Castelli Vascular Surgery, Department of Medicine and Surgery, University of Insubria School of Medicine, Circolo University Teaching Hospital, Varese, Italy aim of reducing cellular metabolic demand $[2,3]$. Despite initial encouraging results both on kidney and liver grafts, continuous organ perfusion was abandoned in favour of SCS, mainly for logistic reasons after the commercialization of new and more effective preservation solutions [4]. Finally, in the 1990s, the increased utilization of less than optimal kidneys from expanded criteria donors (ECD) and non-heart-beating donors (NHBD according to Maastricht classification) gave new interest to this technique [5].

Nowadays, dynamic perfusion (DP) machine is largely adopted for the following advantages:

- Providing nutrition to cellular supply

- Washing out toxins

- Triggering a series of protective mechanisms by innate immune responses and adaptive immune responses

- Evaluating organ function with haemodynamic data

\subsection{The Machine Perfusion}

\subsubsection{Dynamic Perfusion Characteristics and Settings}

During DP, recirculating perfusate is continuously pumped (roller or centrifugal pump) through the organ vasculature by a machine perfusion (MP). There are two modalities of preser- 
vation: in situ (in vivo regional perfusion) and ex situ. During in vivo regional perfusion, a pump sends the perfusate to the graft through the artery, while the vein cannulation guarantees the elimination of the perfusate. In the ex situ modality, after procurement, the graft is placed in an organ chamber and connected to a circuit. In case of liver DP, a separate circulation is sometimes predisposed for the portal vein and hepatic artery through different pumps with different pressure/flow settings.

A heat exchanger regulates temperature from hypothermia $\left(4-10{ }^{\circ} \mathrm{C}\right)$ to sub-normothermia $\left(20-25^{\circ} \mathrm{C}\right)$ and normothermia $\left(35-37^{\circ} \mathrm{C}\right)$.

According to the literature, hypothermic DP should be set by pressure and not by flow velocity, preferring low pressure in avoiding injuries to the graft $[6,7]$. Perfusion can be both continuous (CP) and pulsate (PP), and the perfusate can be nonoxygenated or oxygenated. Generally, hypothermic DP employs acellular perfusates that differ from those used for SCS.

It is noticeable that comparative studies on $\mathrm{PP}$ and $\mathrm{CP}$ did not demonstrate significant outcome benefit in terms of graft survival [8]. Additionally, no difference was seen in terms of renal graft function after transplant [9]. However, continuous flow has been correlated with increased vascular impedance [10] and impaired platelet function [11]. The kidneys are generally treated with PP (25-30 mmHg) [12$15]$. Livers are generally treated with continuous low-pressure flow $(3-5 \mathrm{mmHg}$ ) through the portal vein. The role of hepatic artery perfusion to maintain the peribiliary vascular plexus is still debated $[6,16]$.

The rationale of oxygen supply under hypothermia with acellular perfusate is debated. Firstly, we must underline how oxygen solubility is moderated at atmospheric pressure conditions also at low temperature. Additionally, increased electric charges due to colloidal agents decrease gas solubility. Consequently, the only possibility is to increase partial pressure of oxygen in the perfusate with the aid of a pressurized oxygenator up to $700 \mathrm{mmHg}$. Experimental models of liver and kidney transplant showed significant improvement in the outcome. Nevertheless, we have only a little evidence on possible complications, due to hyperoxygenation as substrate for reactive oxygen species (ROS) [5].

With sub-normothermic DP, both cellular and acellular perfusates are adopted. The kidneys are generally treated with pulsate flow $(40 \mathrm{mmHg})$. Livers are generally treated with continuous lowpressure flow (4-8 $\mathrm{mmHg}$ ) through the portal vein. With normothermic DP, an oxygenated perfusate is always necessary, and an oxygen carrier is mandatory (usually red blood cells) [17, 18]. Near-physiological pressure is used. The kidneys are generally treated with pulsate flow (70$90 \mathrm{mmHg}$ ). Livers are generally treated with continuous flow (60-105 $\mathrm{mmHg}$ ). We have to notice that in case of machine malfunction, hypothermic and sub-normothermic grafts can be rapidly and safely stored with static cold technique. On the contrary, grafts treated with normothermic perfusion will be vulnerable to warm ischemia.

\subsubsection{Organ Preservation Solution}

Anoxia associated with hypothermia triggers a biological cascade driving apoptosis and toxic metabolite production. Goals for preservation solution are:

- Limit ischemia damage during cold preservation.

- Limit reperfusion damage.

- Maintain electrolyte balance.

- Supply metabolites.

The first experimental application of DP, during the 1960s, showed that one of the most relevant complications associated with continuous flow was interstitial oedema and cell swelling. This phenomenon was mainly associated with high capillary resistance. This problem was solved with the development of a new generation of perfusate solution with higher oncotic properties by the addition of hydroxyethyl starch (HES).

The most commonly used cold preservative solutions are:

- ViaSpan (University of Wisconsin solution): High-potassium low-sodium solution, HES, 
adenosine and raffinose. Main disadvantages are high viscosity, tendency for crystallization and risk of hypercalcaemic cardiac arrest.

- Celsior: Low-potassium high-sodium solution, which employs mannitol and lactobionate to decrease cellular oedema.

- Custodiol - histidine-tryptophan-ketoglutarate (HTK): Low-potassium low-viscosity crystalloid not requiring filtering.

- Perfadex: Low-potassium solution lightly buffered dextran-containing, pulmonaryspecific preservation solution.

Actually, Belzer solution is the most commonly used in clinical routine DP. Its main characteristic is the presence of a ribose and a zwitterionic organic buffering agent [2-hydroxy-ethylpiperazine- $N^{\prime}-2$ ethanesulfonic acid (HEPES)].

\subsection{Dynamic Perfusion Impact on Graft Physiology}

\subsubsection{Hypothermia, Sub-normothermia, Adenosine Triphosphate Depletion and Oxygen Free Radical Production}

The rationale of hypothermic preservation is to reduce adenosine triphosphate (ATP) depletion to control the cascade of ischaemic injury. Many physiological processes are driven by ATP and mainly electrolyte balance. In fact, sodium/potassium membrane pump is dependent on ATP, and its depletion is responsible for the loss of electrolyte cellular gradient and membrane integrity. With such a result, cellular oedema and increment of intracellular calcium concentration are seen and, subsequently, phospholipase activation leading to inflammation and apoptosis. During normal oxidative metabolism, ATP breakdown is converted to urea by xanthine dehydrogenase. During ischemia, xanthine dehydrogenase is converted to xanthine oxidase. After reperfusion, in the presence of oxygen, xanthine oxidase transforms the accumulated ATP breakdown into xanthine, and superoxide anion is responsible for lipid peroxidation and cell membrane lesion. ATP metabolism is slowed from 1.5 to 2 times for every $10{ }^{\circ} \mathrm{C}$ drop in temperature [19].

The rationale of sub-normothermic DP is to maintain the graft at a low temperature, reducing metabolism and oxygen requirements, without the risk of cold-induced injuries.

\subsubsection{Dynamic Perfusion, Apoptosis and Inflammation}

Isolated graft tissues produce large quantity of oxygen free radicals that, in association with anoxia, results in mitochondrial damage [20]. Additionally, ROS are involved in many signalling pathway activations, triggering the expression of pro-inflammatory mediators such as interleukins 1 and 6 (IL1, IL6) and tumour necrosis factor alpha (TNF $\alpha$ ), providing for intracellular calcium overload and apoptosis. Inflammation leads to cell proliferation, extracellular matrix (ECM) remodelling and degradation [21]. Vascular cell adhesion molecule-1 (VCAM-1) and e-selectin produce an increment of immunogenicity and subsequent organ damage after graft reperfusion [5]. Tozzi et al. outlined how PP significantly reduces tissue antigen expression of soluble intracellular adhesion molecule-1 (sICAM-1) and pro-inflammatory cytokine (TNF$\alpha$, IL-2 and IL-1 $\beta$ ) compared to SCS controls, resulting in the reduction of leucocyte stimulation (particular neutrophils) and a decrease in postreperfusion activated inflammation-mediated acute-phase proteins that are responsible for ischemia/reperfusion injury (IRI). Many authors have stressed the correlation between IRI, cell apoptosis, delayed graft function (DGF) and chronic renal failure [22, 23]. Apoptosis is a reversible programmed cell death [24]. It is noteworthy that apoptosis is responsible for the loss of renal tubular epithelial cells, chronic tubular atrophy and the loss of podocytes [17, 25-27]. One of the crucial phases of apoptosis is represented by cell membrane degeneration [28]. Many authors focus their attention on ezrin-radixin-moesin (ERM) proteins and plasma membrane-actin cytoskeleton linkers, particularly expressed in epithelial cells $[18,29]$. Ezrin-radixin-moesin proteins are considered anti-apoptotic proteins activated by a 
phosphoinositide 3-kinase signalling pathway (PI3K/AKT/mTOR) [30]. Zhang et al. demonstrated that DP enhances the expression of ERM through PI3K/AKT/mTOR pathway with an antiapoptotic effect. Another crucial element involved in apoptosis is represented by caspase, a protein family that plays a significant role in apoptosis signalling. Among them, Caspase 3 is a key execution molecule that functions in many ways in the apoptotic signal transduction. A significant reduction in activated Caspase 3 was documented in graft cells treated with DP over SCS [31].

In addition to cell apoptosis, ECM damage affects graft functional recovery. Matrix metalloproteinases (MMPs) are a family of calciumdependent zinc-containing gelatinase responsible for ECM remodelling. Overexpression of MMP-2 and MMP-9 is commonly observed after large endothelial damage such as tumour invasion, inflammation or IRI [32]. Metalloproteinases show temporal variability. In particular, MMP-2 and MMP-9 reach a peak of concentration $6 \mathrm{~h}$ after graft reperfusion, subsequently gradually decrease and finally present another peak $24 \mathrm{~h}$ later [33]. Metalloproteinase activation occurs due to ROS and nitric oxide by s-nitrosylation and oxidation [34]. Fu et al. described a lower statistical expression of MMP-9 in PP over SCS [35]. The washout of toxins produced by PP is quite probably responsible for those events.

In contrast to SCS, PP maintains continuous flow with more physiologic haemodynamic forces and promotes microcirculatory perfusion. In fact, fat emboli, lipoprotein aggregation, vasoconstriction and cortical hypoperfusion are responsible for tissue hypoxia and oedema. Furthermore, pulsate perfusion has shown itself to be responsible for microvasculature perfusion improvement and reduction in blood component aggregation [36]. Furthermore, haemodynamic shear stress regulates gene expression of endothelial cells [37, 38], while flow cessation increases pro-thrombotic and inflammatory characteristics of endothelium [39]. In particular, flow stop is associated with the decrease in Kruppel-like factor 2 (KLF-2) expression and with an increase of adhesion molecules. The KLF-2 is a transcription factor that acts as part of the vasoprotective phenotype against thrombosis [40-43].

\subsection{Kidney}

\subsubsection{General Issues and Results of Conventional Grafts}

Although the acute rejection rate is not significantly different between grafts treated with PP or SCS, molecular evidence is clear in terms of DGF and primary nonfunction (PNF) risk reduction [4]. Accordingly, Wight et al., in a systemic review of 20 studies, suggested a $20 \%$ overall reduction of DGF with PP [44]. The limitation of the paper was the inclusion of small and underpowered studies. Nevertheless, results were confirmed by Moers et al. in a randomized trial including 336 paired kidneys confirming an overall reduced incidence of DGF in PP grafts [45]. Schold et al., in a large register retrospective analysis of 907 paired kidneys treated with concluding for PP superiority. Surprisingly, authors demonstrated that prolonged time of pulsate cold ischemia was associated with better results in terms of DGF risk reduction [46]. Interestingly, Chueh et al. emphasized the benefit of prolonged time of pulsate cold ischemia ( $>24 \mathrm{~h}$ ). In fact, due to their remote geographical location, they had the possibility to compare DGF rate and serum creatinine recovery curve of the kidney with an average time of ischemia above 21-23 h. Grafts that received pulsatile perfusion had less delayed graft function $(3.6 \%$ vs $23.4 \%, p=0.02)$ and faster graft recovery $(p<0.001)$ [47].

\subsubsection{Expanded Criteria Donors, Non-heart-Beating Donors and the Role of Haemodynamic Data}

The utility of PP over SCS is even more evident if we focus our attention on ECD and NHBD. Aged ECD grafts are known to have decreased functional capacities and are more susceptible to ischemia-related damage [48]. Grafts from NHBD are subjected to a significant period of warm ischaemic injury (from 10 to $45 \mathrm{~min}$ ) between cardiac arrest and perfusion with cold solution [19]. Over 50\% of the 
kidneys from NHBD suffer from an extended period of DGF, requiring continued dialysis until recovery [49].

The retrospective analysis of 6057 kidney transplants from the Organ Procurement and Transplantation Network (OPTN) showed better results in terms of DGF reduction and was found when the donor age was higher than 60 years [50]. Treckmann et al., in an international randomized controlled trial, enrolled 91 consecutive ECD kidneys, obtaining meaningful results in terms of DGF and PNF risk. In addition, 1-year graft survival resulted significantly higher in the machine-perfused kidney compared with the cold-stored kidney [12]. Conversely, the analysis of 170 kidney transplants from donors older than 65 years from Eurotransplant Senior Program found statistical differences in terms of PNF in PP population over SCS $(3.5 \%$ vs $12.9 \%, p=0.02)$. On the contrary, the overall frequency of DGF was similar in the two groups [4].

Preliminary results of PP applied to graft from NHBD were not equally satisfactory. In fact, a UK multicentre randomized controlled trial conducted in 2010 of 91 kidney transplants from NHBD did not show statistically significant

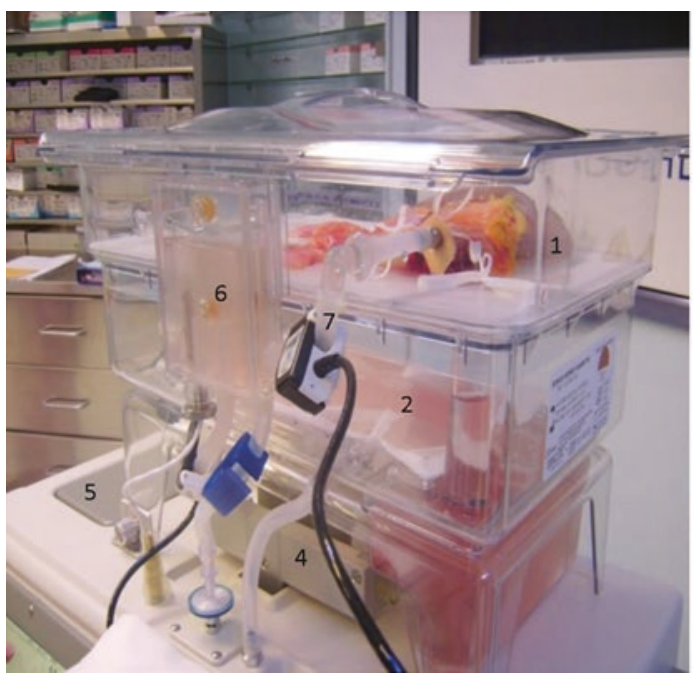

Fig. 13.1 Example of pulsate perfusion machine: (1) kidney graft connected to the circuit, (2) the perfusate excrete through the ureter is filtered by a membrane, (3) the perfusate is collected and (4) sent to the pulsate pump. differences in GFR rate $(53.3 \%$ vs $57.8 \%$, $p=0.8)$ and 1-year graft survival $(93.3 \%$ vs $97.8 \%, p=0.3$ ) between the cohorts of graft treated with SCS and PP. Notably, this study showed a significant difference in terms of acute rejections $(22 \%$ vs $7 \%, p=0.06)$ [13]. On the contrary, a large review of the National Scientific Registry of Transplant Recipient (SRTR) database of 4923 kidney transplants demonstrated how grafts from NHBD stored with SCS technique had a higher risk of DGF. Data analysis suggested PP was beneficial on DGF over SCS in both ECD and NHBD [51]. In our opinion, the encouraging results obtained with perfusion machine are not only explained by the intrinsic benefit of pumped perfusion, especially in this population. In fact, in addition to therapeutic use, pulsatile perfusion machine allows us to obtain fundamental pre-transplantation haemodynamical information: perfusion flow, pressure and intraparenchymal renovascular resistances (Fig. 13.1). These data were correlated by different authors on post-transplant outcome. In fact, it is well demonstrated how elevated vascular resistance is more likely to show reduced survival 1 year after transplant together with increased risk of DGF or PNF.

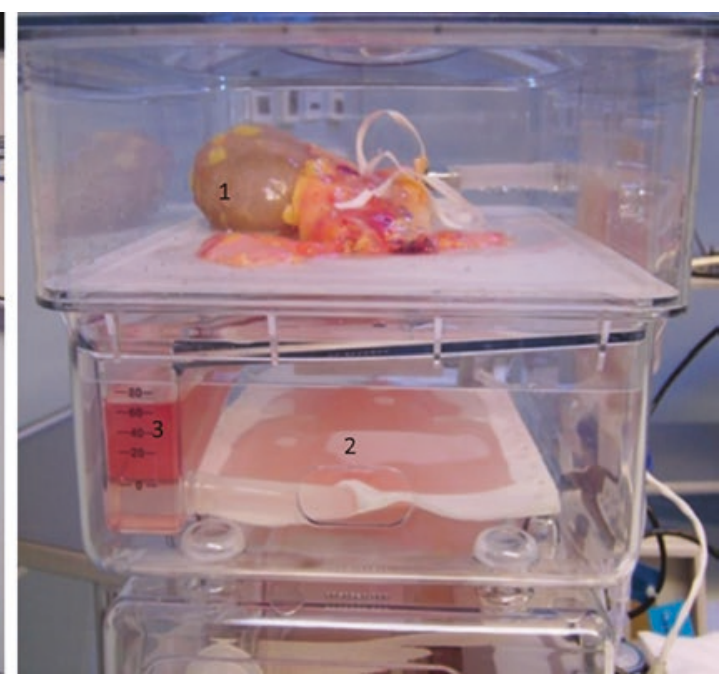

(5) A cooler is responsible for perfusate temperature control. (6) The perfusate is sent to a bubble evacuator and subsequently to the graft. (7) A flow detector gives haemodynamic indices 


\subsection{Other Organs}

Dynamic perfusion was first developed for kidney and liver grafts. From the beginning, it was clear that the kidneys present characteristics that make this treatment safer and with better results. For that reason, PP treatment on the liver, heart, lung and pancreas had been relegated for a long time to a research and preclinical area. The "rediscovery" of DP occurred as consequence of the increased demand for organs and the resulting need to extend the criteria for graft procurement. As seen before, the marginal graft is more affected by hypothermic preservation injury, and consequently new strategies have been required.

\subsubsection{Liver}

Because of its unique anatomy and physiology, the liver is a challenge for DP. In particular, the competition between hepatic artery and portal vein inflow and the sensitivity of hepatic endothelial cells to high pressures are the main problems affecting DP [52, 53]. Organs from the elderly, steatosic or NHBD have elevated risk of moderate to severe preservation injury and related biliary complications [54]. Possible complications are represented by PNF and the need for retransplantation in 3-7\% [55], early allograft dysfunction, cholestasis and infections [56]. The study of DP on animal models started in 1967 at the first attempt to obtain PP of the hepatic artery alone using hypothermic crystalloid solution in hyperbaric oxygen condition with unsatisfactory results [57]. Starzl group proposed the perfusion of both the hepatic artery and the portal vein in a canine model with a solution of blood and preservation solution with excellent results [58]. Soon after, the same procedure was successfully applied to seven patients [59]. Unexpectedly, this technique was never accepted, and static cold storage was largely adopted.

Only at the beginning of the 1980s, Kamada et al. started novel investigation on dynamic hypothermic perfusion [60]. Further investigation on animal models gave promising results
[61]. Guarrera et al. were the first to describe a prospective cohort pilot study in humans. Results confirmed safety and feasibility of liver DP. They did not document any difference in terms of PNF, a small reduction of early allograft dysfunction $(p=0.08)$ and a significant benefit in terms of hospitalization $(p=0.004)$. Further studies comparing DP and SCS are in progress. Many trials are in progress, evaluating both portal vein and combined hepatic artery and portal vein perfusion. Preliminary evidence suggests perfusate oxygenation is necessary to prevent IRI; otherwise, ideal partial oxygen pressure is still unknown [19]. Guarrera et al. reported perfusate oxygen tension $>120 \mathrm{mmHg}$ in an open system without active oxygenation [56]. More data from larger trials on both cold and normothermic continuous preservation are expected.

\subsubsection{Lung}

Steen et al. described first ex vivo lung continuous hypothermic perfusion in clinical use. The most relevant problem researchers found during preclinical phase was pulmonary oedema consequent to endothelial circuit-induced injury and increased vascular resistance. This experience enabled the first pulmonary transplant to be performed with graft from NHBD. The available data does not demonstrate superiority of DP over SCS with conventional grafts [51]; otherwise, Ingermansson and Cypel's experiences proved the advantage of DP for reconditioning of high risk for transplant grafts (pulmonary oedema and/or $\mathrm{PaO} 2$ : $\mathrm{FiO} 2$ < 300) [62, 63]. A portable Organ Care System (OCS) (TransMedics, Andover, MA, US) was commercialized and specifically designed for the reconditioning of marginal lungs. This device is able to perfuse the graft and allows ventilation for continuous alveoli recruitment at the same time. The machine also allows for bronchoscopy during ventilation [64] to be performed. More recently, another ex vivo MP especially designed for marginal lung reconditioning was commercialized by XVIVO Perfusion System (Gothenburg, Sweden). 


\subsubsection{Heart}

The clinical use of DP for the heart has been a particular focus for most researchers. In fact, this technique could represent a fabulous opportunity to extend the type and numbers of heart donors. Additionally, this technique could be used to identify dysfunctional grafts prior to implantation, reducing the risk of death for recipients. Biomarkers of myocardial injury $(\mathrm{pH}$, lactate, troponins) can be measured during perfusion. Additionally, magnetic resonance and coronarography have been proposed for assessment of left ventricular function, anatomy and viability $[52,65]$. A multicentre randomized trial on a new device specifically designed for heart graft perfusion was commercialized by TransMedics' OCS which started in the USA and Europe (PROCEEDII) and demonstrated better outcomes after transplantation in terms of recipient survival and PNF [66].

\subsection{Assessment of Graft Viability and Limits}

Dynamic perfusion offers the attractive feature of providing useful data to assess organ viability before transplant. It may not always be necessary to understand whether the graft was procured under ideal circumstances or from conventional donors. On the contrary, vascular resistance and flow rate can provide useful information on graft quality in case of marginal donors or when particular events occurred during graft harvesting.

The prediction of outcome of the preserved liver is not currently possible, and transplant viability is sought from donor history, organ appearance and microscopical scoring. During DP, the liver does not produce bile. Some authors suggested that perfusate transaminase and lactate dehydrogenase may correlate with transplant outcome, but data are controversial $[56,61]$. For the preserved kidneys, we have a different situation, and 'pour perfusion parameters' have been widely advocated as negative prognostic factors for DGF or PNF. In the literature, the definition of 'poor perfusion parameters' is not univocal. For example, according to Mozes et al., it is defined as resistance inferior to $0.40 \mathrm{mmHg} / \mathrm{mL} / \mathrm{min}$ and superior to $0.60 \mathrm{mmHg} / \mathrm{mL} / \mathrm{min}$ [67]. Guarrera et al. defined poor perfusion parameter as flow inferior to $80 \mathrm{~mL} / \mathrm{min} / 100 \mathrm{~g}$ with resistance above $0.40 \mathrm{mmHg} / \mathrm{mL} / 100 \mathrm{~g}$. De Vries et al. stressed the importance of very high resistance (>3 $\mathrm{mmHg} / \mathrm{mL} / \mathrm{min} / 100 \mathrm{~g}$ ) as a sensitive negative prognostic factor [68, 69]. Accordingly, poor perfusion parameters detected in grafts from ECD and NHBD could be responsible for a higher incidence of graft refusals. The retrospective analysis of 6057 kidney transplants from the Organ Procurement and Transplantation Network (OPTN) partially downgraded the relevance of haemodynamical data emphasizing the risk of possible underutilization of grafts [50]. Although the literature stressed the role of haemodynamic data as an independent risk factor in multivariate analysis for DGF, the evidence to suggest its predictive capacity as a stand-alone parameter is scarce [70]. Jochmans et al. demonstrated low sensitivity and positive predictive value (respectively, $17 \%$ and $40 \%$ ) and acceptable specificity and negative predictive value (93\% and $81 \%$ ) [14]. In a recent prospective study, Gomez et al. compared vascular resistance detected with perfusion machine with post-transplant kidney resistance calculated on Doppler ultrasound without finding any statistical correlation. Additionally, authors did not find any statistical association between renal resistances and DGF $(p=0.58)$ [70]. Those unsatisfactory results can perhaps be explained by the multifactorial nature of DGF or PNF such as obesity, high blood pressure, diabetes mellitus or dyslipidaemia [70, 71]. It is noteworthy that Guarrera et al. assumed that poor perfusion parameters in grafts from donors without other risk factors for DGF should not be taken into count for graft discard [72]. Today, authors suggest organ refusal should be a multidisciplinary choice [50,69]. Haemodynamic data from perfusion machine could be a complementary tool to kidney biopsy scores [71]. 


\section{References}

1. Carrel A, Lindberg CA. The culture of whole organs. Science. 1935;81:621-3.

2. Belzer FO, Ashby BS, Gulyassy PF, Powell M. Successful seventeen-hour preservation and transplantation of human-cadaver kidney. N Engl J Med. 1968;278:608-10.

3. Belzer FO, Southard JH. Principles of solid-organ preservation by cold storage. Transplantation. 1988;45:673-6.

4. Gallinat A, et al. Machine perfusion versus cold storage for the preservation of kidney from donors $\geq 65$ years allocated in the eurotransplant senior programme. Nephrol Dial Transplant. 2012;27:4458-63.

5. Timsit MO, Tullius SG. Hypothermic kidney preservation: a remembrance of the past in the future? Curr Opin Organ Transplant. 2011;16:162-8.

6. Schlegel A, Rougemont O, Graf R, Clavien PA, Dutkowski P. Protective mechanisms of end-ischemic cold machine perfusion in DCD liver grafts. J Hepatol. 2013;58:278-86.

7. Maathuis MH, Manekeller S, van der Plaats A, et al. Improved kidney graft function after preservation using a novel hypothermic machine perfusion device. Ann Surg. 2007;246:982-8.

8. Pegg DE, et al. Renal preservation by hypothermic perfusion. The lack of influence of pulsate flow. Cryobiology. 1976;13:161-7.

9. Gimbrone MA Jr, et al. Endothelial dysfunction, hemodynamic forces, and atherogenesis. Ann N Y Acad Sci. 2000;902:230-9.

10. Travis AR, et al. Vascular pulsatility in patients with a pulsatile- or continuous-flow ventricular assist device. J Thorac Cardiovasc Surg. 2007;133:517-24.

11. Crow $\mathrm{S}$, et al. Comparative analysis of von Willebrand factor profile in pulsatile and continuous left ventricular assist device recipients. ASAIO J. 2010;56:441-5.

12. Treckmann J, Moers C, Smits JM, Gallinat A, Maathuis MH, van Kasterop-Kutz M, Jochmans I, Homan van der Heide JJ, Squifflet JP, van Heurn E, Kirste GR, Rahmel A, Leuvenink HG, Pirenne J, Ploeg RJ, Paul A. Machine perfusion versus cold storage for preservation of kidneys from expanded criteria donors after brain death. Transpl Int. 2011;24(6): 548-54.

13. Watson CJE. Cold machine perfusion versus static cold storage of kidney donated after cardiac death: a UK multicentre randomized controlled trial. Am J Transplant. 2010;10:1991-9.

14. Jochmans I, Moers C, Smits JM, et al. The prognostic value of renal resistance during hypothermic machine perfusion of deceased donor kidneys. Am J Transplant. 2011;11:2214-20.

15. Gallinat A, Fox M, Luer B, Efferz P, Paul A, Minor $\mathrm{T}$. Role of pulsatility in hypothermic reconditioning of porcine kidney grafts by machine perfusion after cold storage. Transplantation. 2013;96:538-42.
16. Guarrera JV, Henry SD, Samstein B, et al. Hypothermic machine preservation in human liver transplantation: the first clinical series. Am J Transplant. 2010;10:372-81.

17. Ichii O, Yabuki A, Sasaki N, et al. Pathological correlations between podocyte injuries and renal functions in canine and feline chronic kidney diseases. Histol Histopathol. 2011;26:1243-55.

18. Fiévet B, Louvard D, Arpin M. ERM proteins in epithelial cell organization and functions. Biochim Biophys Acta. 2007;1773:653-60.

19. Luer B, Koetting M, Efferz P, Minor T. Role of oxygen during hypothermic machine perfusion preservation of the liver. Transpl Int. 2010;23:944-50.

20. Mitchell T, Rotaru D, Saba H, Smith RA, Murphy MP, MacMillan-Crow LA. The mitochondria-targeted antioxidant mitoquinone protects against cold storage injury of renal tubular cells and rat kidneys. J Pharmacol Exp Ther. 2011;336:682-92.

21. Barklin A. Systemic inflammation in the braindead organ donor. Acta Anaesthesiol Scand. 2009;53:425-35.

22. Yoshida M, Honma S. Regeneration of injured renal tubules. J Pharmacol Sci. 2014;124:117-22.

23. Bonventre JV, Yang L. Cellular pathophysiology of ischemic acute kidney injury. J Clin Invest. 2011;121:4210-21.

24. Toronyi E. Role of apoptosis in the kidney after reperfusion. Orv Hetil. 2008;149:305-15.

25. Andrea H, Steven CB. Apoptosis and acute kidney injury. Kidney Int. 2011;80:29-40.

26. Koçkara A, Kayatas M. Renal cell apoptosis and new treatment options in sepsis-induced acute kidney injury. Ren Fail. 2013;35:291-4.

27. Hartleben B, Wanner N, Huber TB. Autophagy in glomerular health and disease. Semin Nephrol. 2014;34:42-52.

28. Kondo T, Takeuchi K, Doi Y, Yonemura S, Nagata S, Tsukita S. ERM (ezrin/radixin/moesin)-based molecular mechanism of microvillar breakdown at an early stage of apoptosis. J Cell Biol. 1997;139: 749-58.

29. Viswanatha R, Bretscher A1, Garbett D. Dynamics of ezrin and EBP50 in regulating microvilli on the apical aspect of epithelial cells. Biochem Soc Trans. 2014;42:189-94.

30. Gautreau A, Poullet P, Louvard D, Arpin M. Ezrin, a plasma membrane-microfilament linker, signals cell survival through the phosphatidylinositol 3-kinase/Akt pathway. Proc Natl Acad Sci U S A. 1999;96:7300-5.

31. Zhang Y, Fu Z, Zhong Z, Wang R, Hu L, Xiong Y, Wang Y, Ye Q. Hypothermic machine perfusion decreases renal cell apoptosis during ischemia/ reperfusion injury via the Ezrin/AKT pathway. Artif Organs. 2016;40(2):129-35.

32. Hamada T, Duarte S, Tsuchihashi S, Busuttil RW, Coito AJ. Inducible nitric oxide synthase deficiency impairs matrix metalloproteinase-9 activity and dis- 
rupts leukocyte migration in hepatic ischemia/reperfusion injury. Am J Pathol. 2009;174:2265-77.

33. Kunugi S, Shimizu A, Kuwahara N, et al. Inhibition of matrix metalloproteinases reduces ischemiareperfusion acute kidney injury. Lab Investig. 2011;91:170-80.

34. Gu Z, Kaul M, Yan B, et al. S-nitrosylation of matrix metalloproteinases: signaling pathway to neuronal cell death. Science. 2002;297:1186-90.

35. Fu Z, Ye Q, Zhang Y, Zhong Z, Xiong Y, Wang Y, Hu L, Wang W, Huang W, Ko DS. Hypothermic machine perfusion reduced inflammatory reaction by downregulating the expression of matrix metalloproteinase 9 in a reperfusion model of donation after cardiac death. Artif Organs. 2016;40(6):E102-11.

36. Patal SK, et al. Effect of increased pressure during pulsatile pump perfusion of deceased donor kidney in transplantation. Transplant Proc. 2012;44:2202-6.

37. McCormick SM, et al. DNA microarray reveals changes in gene expression of shear stressed human umbilical vein endothelial cells. Proc Natl Acad Sci U S A. 2001;98:8955-60.

38. Davies PF. Hemodynamic shear stress and endothelium in cardiovascular pathophysiology. Nat Clin Pract Cardiovasc Med. 2009;6:16-26.

39. Garcia-Cardena G, et al. Biochemical activation of vascular endothelium as a determinant of its functional phenotype. Proc Natl Acad Sci U S A. 2001;98:4478-85.

40. Fledderus JO. Prolonged shear stress and KLF2 suppress constitutive proinflammatory transcription through inhibition of ATF2. Blood. 2007;109: 4249-57.

41. Dekker RJ, van Thienen JV, Rohlena J, de Jager SC, Elderkamp YW, Seppen J, de Vries CJ, Biessen EA, van Berkel TJ, Pannekoek H, Horrevoets AJ. Endothelial KLF2 links local arterial shear stress levels to the expression of vascular tone-regulating genes. Am J Pathol. 2005;167(2):609-18.

42. Dekker RJ, Boon RA, Rondaij MG, Kragt A, Volger OL, Elderkamp YW, Meijers JC, Voorberg J, Pannekoek H, Horrevoets AJ. KLF2 provokes a gene expression pattern that establishes functional quiescent differentiation of the endothelium. Blood. 2006;107(11):4354-63.

43. van Thienen JV, Fledderus JO, Dekker RJ, Rohlena J, van Ijzendoorn GA, Kootstra NA, Pannekoek H, Horrevoets AJ. Shear stress sustains atheroprotective endothelial KLF2 expression more potently than statins through mRNA stabilization. Cardiovasc Res. 2006;72(2):231-4.

44. Wight JP, Chilcott JB, Holmes MW, Brewer N. Pulsatile machine perfusion vs. cold storage of kidneys for transplantation: a rapid and systematic review. Clin Transpl. 2003;17(4):293-307.

45. Moers C, Smits JM, Maathuis MH, Treckmann J, van Gelder F, Napieralski BP, van Kasterop-Kutz M, van der Heide JJ, Squifflet JP, van Heurn E, Kirste GR, Rahmel A, Leuvenink HG, Paul A, Pirenne J, Ploeg RJ. Machine perfusion or cold storage in deceased- donor kidney transplantation. $\mathrm{N}$ Engl $\mathrm{J}$ Med. 2009;360(1):7-19.

46. Schold JD, Kaplan B, Howard RJ, Reed AI, Foley DP, Meier-Kriesche HU. Are we frozen in time? Analysis of the utilization and efficacy of pulsatile perfusion in renal transplantation. Am J Transplant. 2005;5(7):1681-8.

47. Chueh S-CJ. The benefit of pulsate machine perfusion of standard criteria deceased donor kidney at a geographically remote transplant center. ASAIO J. 2014;60(1):76-80.

48. Ruggenenti P. Ways to boost kidney transplant viability: a real need for the best use of older donors. Am J Transplant. 2006;6:2543-7.

49. Wells AC. Donor kidney disease and transplant outcome for kidney donated after cardiac death. Br J Surg. 2009;96:299-304.

50. Cantafio AW, et al. Risk stratification of kidney from donation after cardiac death donors and the utility of machine perfusion. Clin Transpl. 2011;25:e530-40.

51. Lodhi SA, Lamb KE, Uddin I, Meier-Kriesche HU. Pulsatile pump decreases risk of delayed graft function in kidneys donated after cardiac death. Am J Transplant. 2012;12(10):2774-80.

52. Balfoussia D, et al. Advances in machine perfusion graft viability assessment in kidney, liver, pancreas, lung, and heart transplant. Exp Clin Transplant. 2012;10:87-100.

53. Op den Dries $\mathrm{S}$, et al. Ex vivo normothermic machine perfusion and viability testing of discarded human donor livers. Am J Transplant. 2013;13:1327-35.

54. Maheshwi A, et al. Biliary complications and outcome of liver transplant from donors after cardiac death. Liver Transpl. 2007;13:1645-53.

55. Plaeg RJ, et al. Risk factors for primary dysfunction after liver transplantation-a multivariate analysis. Transplantation. 1993;55:807-13.

56. Guarrera JV, et al. Hypothermic machine perfusion in human liver transplantation: the first clinical series. Am J Transplant. 2010;10:372-81.

57. Slapak M, et al. Twenty-four hours liver preservation by the use of continuous pulsate perfusion and hyperbaric oxygen. Transplantation. 1967;5(s):1154-8.

58. Brettschneider L, et al. The use of combined preservation technique for extended storage of orthotopic liver homografts. Surg Gynecol Obstet. 1968; 126:263.

59. Brettschneider L, et al. Experimental and clinical preservation of orthotopic liver homograft. In: Norman J, editor. Organ perfusion and preservation. New York: Allpeton-Century Crofts; 1968. p. $271-84$.

60. Kamada N, et al. Orthotopic rat liver transplantation after long-term preservation by continuous perfusion with fluorocarbon emulsion. Transplantation. 1980;30:43-8.

61. Guarrera JV, et al. Hypothermic machine perfusion of liver graft for transplantation: technical development in human discard and miniature swine models. Transplant Proc. 2005;37:323-5. 
62. Ingemansson R, Eyjolfsson A, Mared L, et al. Clinical transplantation of initially rejected donor lungs after reconditioning ex vivo. Ann Thorac Surg. 2009;87:255-60.

63. Cypel M, Yeung JC, Liu M, et al. Normothermic ex vivo lung perfusion in clinical lung transplantation. N Engl J Med. 2011;364:1431-40.

64. Mohite P, Sabashnikov A, Garcia Saez D, et al. Utilization of the organ care system lung for the assessment of lungs form a donor after cardiac death (DCD) before bilateral transplantation. Perfusion. 2014;29:1-4.

65. Ciubotaru A, Haverich A. Ex vivo approach to treat failing organs: expanding the limits. Eur Surg Res. 2015;54:64-74.

66. Koerner MM, Ghodsizad A, Schulz U, et al. Normothermic ex vivo allograft blood perfusion in clinical heart transplantation. Heart Surg Forum. 2014;17:E141-5.

67. Mozes MF, Skolek RB, Korf BC. Use of perfusion parameters in predicting outcomes of machinepreserved kidneys. Transplant Proc. 2005;37:350-1.

68. Jochmans I, Moers C, Smits JM, Leuvenink HG, Treckmann J, Paul A, Rahmel A, Squifflet JP, van Heurn E, Monbaliu D, Ploeg RJ, Pirenne J. Machine perfusion versus cold storage for the preservation of kidneys donated after cardiac death: a multicenter, randomized, controlled trial. Ann Surg. 2010;252(5):756-64.
69. de Vries EE, Hoogland ER, Winkens B, Snoeijs MG, van Heurn LW. Renovascular resistance of machineperfused DCD kidneys is associated with primary nonfunction. Am J Transplant. 2011;11(12):2685-91.

70. Gómez V, Orosa A, Rivera M, Diez-Nicolás V, Hevia V, Alvarez S, Carracedo D, Ramos E, Burgos FJ. Resistance index determination in the pre and post kidney transplantation time points in graft dysfunction diagnosis. Transplant Proc. 2015;47(1):34-7.

71. Paredes-Zapata D, Ruiz-Arranz A, Rodriguez-Villar C, Roque-Arda R, Peri-Cusi L, Saavedra-Escobar S, Vizcaino-Elias F, Garcia-Rodriguez X, BohilsValle M, Rodriguez-Peña S, Quijada-Martorell M, Gonzalez-Rodriguez JJ, Oppenheimer-Salinas F, Alcaraz-Asensio A, Adalia-Bartolome R. Does the pulsatile preservation machine have any impact in the discard rate of kidneys from older donors after brain death? Transplant Proc. 2015;47(8):2324-7.

72. Guarrera JV, Goldstein MJ, Samstein B, et al. When good kidneys pump badly: outcomes of deceased donor renal allografts with poor pulsatile perfusion characteristics. Transpl Int. 2010;23:444-6.

73. Weeder PD, van Rijn R, Porte RJ. Machine perfusion in liver transplantation as a tool to prevent non-anastomotic biliary strictures: rationale, current evidence and future directions. J Hepatol. 2015;63:265-75.

74. Steen S, Sjo“berg T, Pierre L, Liao Q, Eriksson L, Algotsson L. Transplantation of lungs from a nonheart-beating donor. Lancet. 2001;357:825-9. 